\title{
Middlebrook 7H11 Growth Medium
}

National Cancer Institute

\section{Source}

National Cancer Institute. Middlebrook 7 H11 Growth Medium. NCI Thesaurus. Code C85510.

A modification to the solid $7 \mathrm{H} 10$ growth medium that is enriched by the addition of an enzymatic digest of casein. 